\title{
COVID-19: Un gran desafío para la salud pública y la economía en Colombia
}

Como citar este artículo:

Ferreira Cáceres M, Ramírez Cuadros C, Matta Oyola P, Barrera Cruz Y. COVID-19: Un gran desafío para la salud pública y la economía de Colombia. Revista Cuidarte. 2020; 11(3):e1318. http://dx.doi.org/10.15649/cuidarte.1318

Revista Cuidarte

Rev Cuid. 2020; 11(3): e1318

doi) $h$ ttp://dx.doi.org/10.15649/cuidarte. 1318

E-ISSN: 2346-3414

(1) María Mercedes Ferreira Cáceres ${ }^{1}$ (1) Cindy Gabriela Ramírez Cuadros² (1) Piedad Gabriela Matta Oyola ${ }^{3}$

(1) Yislem Audrey Barrera Cruz ${ }^{4}$

1 Universidad Autónoma de Bucaramanga. Bucaramanga, Colombia.

E-mail:mferreira@unab.edu.co

2 Universidad autónoma de

Bucaramanga. Bucaramanga, Colombia. E-mail:

cramirez221@unab.edu.co

3 Universidad autónoma de

Bucaramanga. Bucaramanga, Colombia.

E-mail: pmatta@unab.edu.co

4 Universidad autónoma de Bucaramanga. Bucaramanga, Colombia. E-mail:

ybarrera737@unab.edu.co Autor de Correspondencia
La pandemia COVID - 19 está generando una gran crisis global en la que los países en desarrollo parecen ser los más afectados; en América Latina y el Caribe resulta preocupante dadas las precarias condiciones laborales y al alto índice de pobreza. El mercado laboral colombiano está seriamente perjudicado por el aislamiento social adoptado para desacelerar los contagios de COVID-19', sin embargo, son incontables las pérdidas humanas y económicas por esta pandemia que no discrimina. Enfrentar este enemigo invisible con prudencia y sensatez será la hazaña más grande de nuestra historia y la forma de lograrlo será nuestro más preciado legado para las
Enfrentar este enemigo invisible con prudencia y sensatez será la hazaña más grande de nuestra historia y la forma de lograrlo será nuestro más preciado legado para las generaciones venideras.
La Organización Mundial de la Salud (OMS) orienta a un actuar coordinado y de gran alcance que este al nivel de la magnitud de la problemática de salud pública que se vive actualmente; de la misma manera para las Naciones Unidas el llamado es uno solo a generar una estrategia global, multilateral y solidaria que le brinde al mundo no solo la cura contra el virus, sino las soluciones a las consecuencias de una crisis socioeconómica que se agudiza en las comunidades y naciones más vulnerables².

La economía de un país depende de múltiples actores y está en nuestras manos construir un futuro en donde los decesos humanos no ocurran por la carencia económica, la pobreza y la indiferencia hacia un sistema de salud frágil e inestable ${ }^{3}$ porque entonces la lucha por cuidar la vida habrá sido en vano. Si no se toman pronto acciones de política pública más agresivas, la tasa de desempleo podría superar fácilmente el $20 \%$, como ocurrió en la re-

Recibido: junio 17 de 2020

Aceptado: julio 10 de 2020

Publicado:septiembre 1 de 2020 $\square *$ Correspondencia

Yislem Audrey Barrera Cruz

E-mail:ybarrera737@unab.edu.co 
cesión de 1999. Un aumento masivo del desempleo y la ruptura del tejido empresarial podría hacer que esta crisis tuviera efectos persistentes con un mercado laboral deprimido ${ }^{1}$ en medio de una enfermedad que parece perpetuarse. En este contexto la pandemia ha dejado vulnerables a las mujeres, las personas mayores, los jóvenes, los trabajadores informales, las micro, pequeñas y medianas empresas (MiPyMEs), el sector no estructurado y los grupos que se encuentran en situaciones humanitarias y de conflicto. Así, una caída en la productividad y que esta nos lleve a una depresión económica sería el panorama más sombrío y quizás puede representar una verdadera enfermedad de la cual sea difícil recuperarnos ${ }^{10}$. No se trata de reiniciar completamente sino de recuperar vida productiva, proteger la salud y aquellos con mayor riesgo y vulnerabilidad.

A nivel de Colombia, es importante mencionar que la economía para el año 2019 tuvo un incremento del 3,3\% frente a un $0,1 \%$ de América Latina y el Caribe, datos tomados según CEPAL, $2020^{4}$. Motivo por el cual se esperaba continuar con dicho aumento durante este año, sin embargo, para el primer trimestre se presentaron 2 actores que afectaron gravemente la economía a nivel mundial, estos fueron en primera instancia la diseminación del Covid-19 y a su vez la caída del precio del petróleo. Millonarias son las pérdidas económicas que se pronostican cada mes; estas cifras económicas varían entre $\$ 4,6$ billones y $\$ 59$ billones por mes, cifras que representan entre $0,5 \%$ y $6,1 \%$ del PIB nacional ${ }^{5}$. Hoy por hoy la rama de la economía es la más afectada a causa del COVID -19; sin embargo, actividades como turismo, alimentación, servicios administrativos e inmobiliarios, construcción y el comercio formal e informal son las partes que mayormente están siendo golpeadas por la pandemia 6 .

Los efectos negativos en el ámbito económico son múltiples y en muchas ocasiones complejos de abordar; si se habla del trabajo formal inmediatamente aparecen temas como la caída de los salarios o los despidos laborales sean justificados o no"; con respecto al trabajo informal existe la disyuntiva entre conseguir el sustento y exponerse al virus o a una sanción económica en el marco del incumplimiento del distanciamiento social obligatorio. Se estima que un $42,4 \%$ del empleo corresponde a los sectores ubicados en riesgo y con más alto grado de afectación por las medidas del aislamiento social; las MiPyMEs encierran el drama no solo de todo un sector de servicios al borde de la quiebra, sino de familias completas, todos en la incertidumbre y la ansiedad de como salvaguardarse unos a otros en tanto observan a la distancia como sus ahorros o prestamos se hunden junto con las extensiones de las cuarentenas que pretenden jugar con el numero de enfermos, pero nada saben del número de desempleados ${ }^{1}$.

Sin una posibilidad definitiva para controlar esta emergencia sanitaria de orden mundial son imprescindibles las medidas establecidas por la OMS para evitar la transmisión rápida y descontrolada del virus SARS-COV-2 así como los protocolos adecuados de bioseguridad que permitan mediante diversas estrategias reactivar las áreas productivas de la sociedad como mecanismo para evitar una mayor contracción económica o es posible según estimaciones que la deuda bruta del Gobierno nacional ascienda a $61 \%$ del PIB en 2020, aumentando 10,7 puntos respecto al $2019^{7}$.

Esta problemática de interés internacional en salud publica adquiere un tinte moral cuando los derechos sociales, económicos y en salud convergen ${ }^{8}$, según predicciones del banco interamericano de desarrollo el mundo se encuentra ad portas de una recesión en la que no solo los profesionales de salud, el sistema sanitario y las políticas públicas están a prueba, sino también las instituciones de los estados y por supuesto las cabezas de Gobierno quienes están afrontando el desafío de controlar esta pandemia e implementar medidas para afrontar el desempleo y la caída del producto interno bruto. Así, surge el dilema de sobreponer la economía a los derechos 
humanos o manejarlos de forma equiparable y aunque puede resultar complejo y engañoso es posible llegar a un punto de encuentro ${ }^{8}$. Aquellos con posiciones privilegiadas, la comunidad científica y todos los que cuentan con un grado de influencia son llamados a desempeñar un papel crítico, activo y constructivo para impulsar a los líderes de estado a proteger la vida y la economía y de este modo asegurar y garantizar que la oferta de bienes y servicios se mantenga activa durante y después de la pandemia ${ }^{3}$.

La humanidad debe asumir con sabiduría y con una visión holística esta situación, comprendiendo que la salud pública y la economía hacen parte de un todo y no son mutuamente excluyentes. El aislamiento social es la mejor herramienta que tenemos en este momento, sin embargo, que tan sostenible es esta medida para la sociedad y los países en desarrollo, cual es el numero en cifras y en vidas humanas dispuestos a soportar por la pandemia que ahora se ve fuertemente amenazada por falta de recursos

Estamos ante el reto más grande de la salud pública y es el momento de orientar la economía hacia una salud y una vida digna, promover la salud y salvaguardar la economía. económicos en donde muchas personas están pasando de la pobreza a la miseria ${ }^{3}$. Es el momento de equilibrar la balanza entre cómo controlar la que tal vez sea la infección más grave de este siglo y como evitar que la pobreza empeore esta situación en una sociedad que se rehúsa a una profunda recesión económica y a la pérdida de más vidas humanas que día a día se suman a las estadísticas nacionales. Estamos ante el reto más grande de la salud pública y es el momento de orientar la economía hacia una salud y una vida digna, promover la salud y salvaguardar la economía.

Agradecimientos: Expresamos nuestro agradecimiento al Dr. Wilson Cañón Montañez, por su colaboración en la revisión del manuscrito.

Conflicto de intereses: Los autores declaran que no hay conflicto de intereses

\section{Referencias}

1. López Jl, Romero JC, Contreras MP. Salvaguardar el empleo. Corficolombiana. Publicado en línea el 4 de mayo, 2020. Disponible en: https://investigaciones.corficolombiana.com/ documents/38211/0/EES04052020.pdf/78bb4faa-b1 cf-5a61-e866-1a908d74f90c

2. United Nations. Shared responsibility, Global solidarity: Responding to the socio-economic impacts of COVID-19. United Nations. Publicado en línea en Marzo, 2020 Disponible en: https://unsdg.un.org/resources/shared-responsibility-global-solidarity-responding-socio-economic-impacts-covid-19

3. Williams DR, Cooper LA. COVID-19 and health equity - A new kind of "Herd immunity". JAMA. 2020;323(24):2478-2480. https://doi.org/10.1001/jama.2020.8051

4. Barcena A, Pinheiro V. El trabajo en tiempos de pandemia: Desafíos frente a la enfermedad por coronavirus (COVID-19). CEPAL/OIT. 2020. Disponible en: https://www.cepal.org/sites/ default/files/presentation/files/ppt_version_final_oit-cepal-_covid-19_-_21-05-20.pdf

5. Baker SR, Bloom N, Davis SJ, Terry S. COVID- induced economic uncertainty. National Bureau of Economic Research Inc. Published online April 2020. NBER working paper series. No. w26983. https://doi.org/10.3386/w26983

6. Bonet JA, Marín D, Pérez GJ, Galvis LA, Haddad EA, Araujo IF, et al. Impacto económico regional del Covid-19 en Colombia: un análisis insumo-producto. Documento de trabajo sobre economía regional y urbana. Banco de la República. 2020;288:1-34.

https://doi.org/10.32468/dtseru.288 
7. Romero JC, López Jl, Nieto AV. Financiación inteligente. Corficolombiana. Publicado en línea el 11 de mayo, 2020. Disponible en: https://investigaciones.corficolombiana.com/documents/38211/0/EES11052020\%20(1).pdf/cf0ad7f6-1dde-89a7-6502-3d268abe35ac

8. Bohoslavsky, J. COVID-19 Economía versus derechos humanos: una dicotomía engañosa. Health and Human Rights Journal. Publicado en línea en Abril 20, 2020. Disponible en:

https://www.hhrjournal.org/2020/04/covid-19-economy-vs-human-rights-a-misleading-dichotomy/

9. Alradhawi M, Shubber N, Sheppard J, Ali Y. Effects of the COVID-19 pandemic on mental well-being amongst individuals in society - A letter to the editor on "The socio-economic implications of the coronavirus and Covid-19 pandemic: A review". Int J Surg. 2020;78:147-148. https://doi.org/10.1016/j.ijsu.2020.04.070

10.Williams G, Cañon-Montañez W. COVID-19: What we've learned so far. Revista Cuidarte. 2020;11(2):e1225. http://dx.doi.org/10.15649/cuidarte.1225 